\title{
The Impact of Conduction Angle on Short Circuit Calculations in Case of Three Phase Fault for a FACTS Controlled Transmission Line in the Algerian Network
}

\author{
Mohamed ZELLAGUI \\ LSP-IE Laboratory, \\ Department of Electrical Engineering, \\ Faculty of Technology, \\ University of Batna, Algeria \\ m.zellagui@ymail.com
}

\author{
Heba Ahmed HASSAN \\ College of Engineering, Dhofar \\ University, Sultanate of Oman \\ Faculty of Engineering, Cairo \\ University, Giza, Egypt \\ hebahassan@ieee.org
}

\author{
Abdelaziz CHAGHI \\ LSP-IE Laboratory, \\ Department of Electrical Engineering, \\ Faculty of Technology, \\ University of Batna, Algeria \\ az_chaghi@univ-batna.dz
}

\begin{abstract}
This paper presents the impact study of using series Flexible AC Transmission System (FACTS) devices, Thyristor Controlled Series Capacitor (TCSC), GTO Controlled Series Capacitor (GCSC) and Thyristor Controlled Series Reactor (TCSR), on the short circuit parameters of a $400 \mathrm{kV}$ single electrical transmission line in case of three phase fault. The case study is an electrical transmission line in the Algerian transmission network which is compensated by each of the three mentioned devices at its midpoint. Simulations results investigate the impact of the conduction angle of FACTS power electronic devices on the short circuit parameters of the line in case of three phase fault. The obtained results verify the presented theoretical analysis of short circuit calculations.
\end{abstract}

Keywords - Series FACTS Devices, Conduction Angle, Apparent Reactance, Three Phase Fault, Symmetrical Components.

\section{INTRODUCTION}

Electrical power systems have to be planned, projected, constructed, commissioned and operated in such a way to enable a safe, reliable and economic supply of the load. The knowledge of equipment loading at the time of commissioning and the prediction for design and determination of the rating of each individual equipment and that of the power system as a whole is necessary in the future. Faults in power systems cannot be avoided despite careful planning and design, good maintenance and thorough operation of the system. This implies influences from outside the system, such as faults following lightning strokes into phase-conductors of overhead lines and damages of cables due to earth construction works, as well as internal faults due to ageing of insulation materials [1-2]. Fault currents have an important influence on the design and operation of equipment and power systems. In the Algerian Company of Electrical and Gas, more than $83 \%$ of the occurring faults on 220 and $400 \mathrm{kV}$ power systems overhead transmission networks are single phase to ground type and $11 \%$ are phase to phase faults, and $6 \%$ are three phase faults, [3].

Recent research has focused on the impact of three phase short circuit fault on electrical devices, specially transmission lines. Reference [4] looked at three phase circuit analysis based fault location on transmission line while [5] presents a new impedance based fault location method in the case of phase to phase and three phase faults. That method utilized the measured impedance by distance relay and super imposed current factor, which is the ratio of post-fault current to super impose current, to discriminate the fault position on the line. Reference [6] proposes a novel fault feature extraction that could be used in fault detection and classification schemes based on single-end measurements using time shift invariant property of a sinusoidal waveform. In [7], the impact of fault resistance, for a transmission line compensated by series FACTS devices, has been investigated in the case of phase to earth fault. However, three phase electrical machines performances under various grid faults have been investigated in [8-13]. On the other hand, [14-15] discuss the performance of a grid-connected photovoltaic system under various grid faults. Reference [16] has proposed a method that can be developed from two matrices and used to solve the various types of single or simultaneous unsymmetrical faults with hybrid compensation for microgrid (MG) distribution systems.

Recently, the substantial increase of power demand, and the limited expansion of power generation and transmission due to scarcity of resources and environmental restrictions have been noticed. As a consequence, some transmission lines are heavily loaded and the system stability becomes a power transfer-limiting factor. Flexible AC transmission systems (FACTS) controllers have been mainly used for solving various power system steady state control problems [17-18]. The presence of the FACTS devices in the faulted loop introduces changes to the short circuit parameters seen by the distance relay and overcurrent relay.

In this paper, the impact of the controlled series FACTS device, i.e. TCSC, GCSC and TCSC, is investigated in case of three phase fault at the end of the $400 \mathrm{kV}$ transmission line in the Algerian power network. These devices are located on the midline between the two 400/200kV substations, Salah Bey (Sétif) and Bir Ghbalou (Bouira), which are protected by distance relays. The study presents the impact of the conduction angle on the short circuit parameters i.e.: symmetrical currents $\left(I_{l}, I_{2}\right.$ and $\left.I_{0}\right)$, transmission line currents $\left(I_{A}, I_{B}\right.$ and $\left.I_{C}\right)$, symmetrical 
voltages $\left(V_{l}, V_{2}\right.$ and $\left.V_{0}\right)$, and transmission line voltages $\left(V_{A}\right.$, $V_{B}$ and $\left.V_{C}\right)$.

\section{MODELLING OF APPARENT REACTANCE CONTROLLED BY SERIES FACTS DEVICES}

\section{A. TCSC}

The TCSC consists of a capacitance $(C)$ connected in parallel with an inductance $(L)$ which is controlled by a valve mounted in anti-parallel conventional thyristors $\left(T_{1}\right.$ and $T_{2}$ ). Thyristors are controlled by the conduction angle $(\alpha)$ which varies between $90^{\circ}$ and $180^{\circ}$. This compensator can be modeled as a variable apparent reactance $\left(X_{T C S C}\right)$ as shown in Fig. 1.

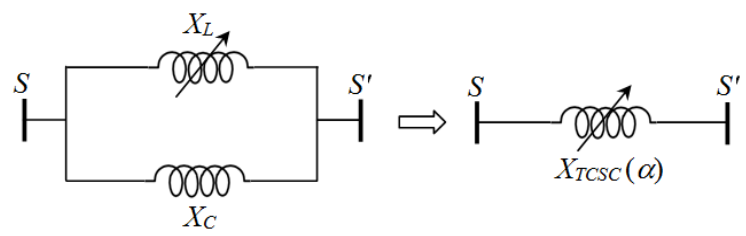

Figure 1. Apparent reactance controlled by TCSC.

This compensator injects a variable apparent reactance $\left(X_{T C S C}\right)$ as shown in Fig. 1. Its value is a function of the line reactance $X_{L}$ where the device is located. The apparent reactance $X_{T C S C}$, [17-19], is defined as:

$$
X_{T C S C}(\alpha)=X_{L}(\alpha) / / X_{C}=\frac{X_{L}(\alpha) \cdot X_{C}}{X_{L}(\alpha)+X_{C}}
$$

The expression of $X_{T C S C}$ is directly related to the conduction angle $\alpha$, which is varied according to the following equation:

$$
X_{L}(\alpha)=X_{L \max }\left[\frac{\pi}{\pi-2 \alpha-\sin (2 \alpha)}\right]
$$

where,

$$
X_{L \max }=L . \omega \text { and } X_{C}=\frac{1}{C . \omega}
$$

Substituting by equations (2) and (3), equation (1) becomes:

$$
X_{T C S C}(\alpha)=\frac{X_{C} \cdot X_{L}\left[\frac{\pi}{\pi-2 \alpha-\sin (2 \alpha)}\right]}{X_{C}+X_{L}\left[\frac{\pi}{\pi-2 \alpha-\sin (2 \alpha)}\right]}
$$

\section{B. GCSC}

The GCSC is the first in the family of series compensators. It consists of a capacitance $(C)$ connected in series with the electrical transmission line and controlled by a valve-type GTO thyristors mounted in anti-parallel $\left(G_{1}\right.$ and $G_{2}$ ) and controlled by a firing angle $(\gamma)$. The firing angle varies between $0^{\circ}$ and $180^{\circ}$, [20-21]. This compensator can be modeled as a variable apparent reactance $\left(X_{G C S C}\right)$ as shown in Fig. 2.

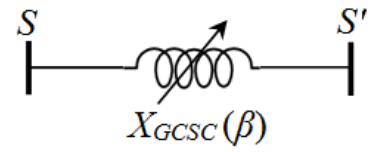

Figure 2. Apparent reactance controlled by GCSC.

This compensator installed in midline of the transmission line $A B$, between busbars $A$ (source) and $B$ (load), can be modeled as a variable apparent capacitive reactance $\left(X_{G C S C}\right)$. From Fig. 3, this capacitive reactance is defined as [21]:

$$
\begin{gathered}
\qquad X_{G C S C}(\gamma)=X_{C . M a x}\left[1-\frac{2}{\pi} \gamma-\frac{1}{\pi} \sin (2 \pi)\right] \\
\text { where, } \quad X_{C . M a x}=1 / C_{G C S C} . \omega
\end{gathered}
$$

The conduction angle $(\beta)$, which varies between 0 to $90^{\circ}$, is defined as:

$$
\beta=\pi-2 \gamma=2\left(\frac{\pi}{2}-\gamma\right)
$$

From equation (3), the equation (2) becomes:

$$
X_{G C S C}(\beta)=X_{C . M a x}\left[1-\left(\frac{\pi-\beta}{\pi}\right)-\frac{1}{\pi} \sin (\pi(\pi-\beta))\right]
$$

\section{TCSR}

The TCSR consists of variable inductance $\left(L_{l}\right)$, connected in series with the transmission line, controlled by thyristors mounted in anti-parallel $\left(T_{1}\right.$ and $\left.T_{2}\right)$. Thyristors are controlled by the conduction angle $(\alpha)$ which varies between $90^{\circ}$ and $180^{\circ}$, and a fixed value inductance $\left(L_{2}\right)$ connected in shunt [22-23]. This compensator can be modeled as a variable apparent inductive reactance $\left(X_{T C S R}\right)$ as shown in Fig. 3.

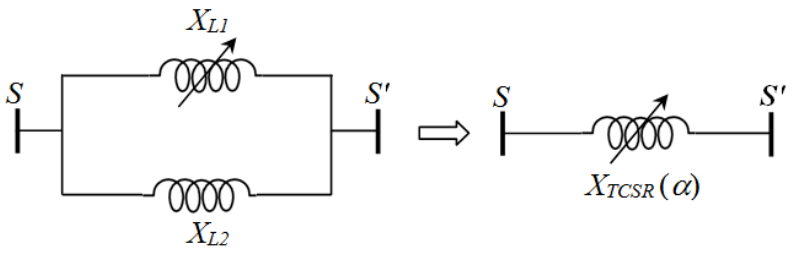

Figure 3. Apparent reactance controlled by TCSR.

From Fig. 3, the apparent reactance of the TCSR which is injected on the transmission line, [22-23], is defined as:

$$
X_{T C S R}(\alpha)=X_{L 1}(\alpha) / / X_{L 2}=\frac{X_{L 1}(\alpha) \cdot X_{L 2}}{X_{L}(\alpha)+X_{L 2}}
$$

The reactance of the first inductance $X_{L I}(\alpha)$ controlled by thyristors is defined as: 


$$
X_{L 1}(\alpha)=X_{L 1-\max }\left[\frac{\pi}{\pi-2 \alpha-\sin (2 \alpha)}\right]
$$

where,

$$
X_{L 1-\max }=L_{1} \cdot \omega
$$

and,

$$
X_{L 2}=L_{2} . \omega
$$

Substituting by equations (10), (11) and (12), equation (9) becomes:

$$
X_{T C S R}(\alpha)=\frac{L_{2} L_{1} \omega^{2}\left(\frac{\pi}{\pi-2 \alpha-\sin (2 \alpha)}\right)}{\omega\left(L_{2}+L_{1}\left(\frac{\pi}{\pi-2 \alpha-\sin (2 \alpha)}\right)\right)}
$$

In the presence of series FACTS devices, the new impedance of the transmission line $\left(Z_{A B-F A C T S}\right)$ is defined as:

$$
Z_{A B-F A C T S}=R_{L}+j\left[X_{L} \pm X_{F A C T S}(\text { Angle })\right]
$$

where, $\alpha$ and $\beta$ are the controlled conduction angles of thyristors and GTO, respectively.

\section{THREE PHASE FAULT CURRENT CALCULATIONS IN THE PRESENCE OF SERIES FACTS DEVICES}

Fig. 4 shows the equivalent circuit for transmission line in case of a three phase fault at busbar $B$, in the presence of a series FACTS device inserted at the mid of the line.

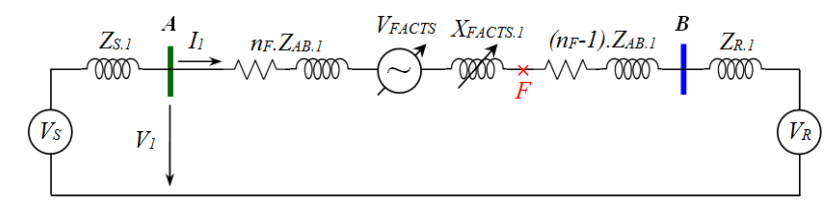

Figure 4. Three phase fault equivalent circuit in the presence of series FACTS device.

The basic equations for this type of fault for the three phases voltages, [1, 24-26], are defined as:

$$
V_{A}=V_{B}=V_{C}=0
$$

By considering the equivalent circuit of Fig. 5:

$$
V_{1}=V_{S} \pm V_{F A C T S}-Z_{A B .1}^{F A C T S} \cdot I_{1}=0
$$

where, $Z_{A B .1}^{F A C T S}=n_{F} \cdot Z_{A B .1} \pm X_{F A C T S}+\left(1-n_{F}\right) \cdot Z_{A B .1}$

$V_{2}=-\underbrace{\left[n_{F} \cdot Z_{A B .2} \pm X_{F A C T S}+\left(1-n_{F}\right) \cdot Z_{A B .2}\right]}_{\neq 0} \cdot I_{2}=0$

$V_{0}=-\underbrace{\left[n_{F} \cdot Z_{A B .0} \pm X_{F A C T S}+\left(1-n_{F}\right) \cdot Z_{A B .0}\right]}_{\neq 0} \cdot I_{0}=0$
From equations (17), (18) and (19), the symmetrical components of the currents are:

$$
\begin{gathered}
I_{1}=\frac{V_{S} \pm V_{F A C T S}}{n_{F} \cdot Z_{A B .1} \pm X_{F A C T S}+\left(1-n_{F}\right) \cdot Z_{A B .1}} \\
I_{2}=0 \\
I_{0}=0
\end{gathered}
$$

The matrix representing the symmetrical components of the three phase currents, [27-28], are:

$$
\left[\begin{array}{l}
I_{0} \\
I_{1} \\
I_{2}
\end{array}\right]=\frac{1}{3}\left[\begin{array}{ccc}
1 & 1 & 1 \\
1 & a & a^{2} \\
1 & a^{2} & a
\end{array}\right]\left[\begin{array}{l}
I_{A} \\
I_{B} \\
I_{C}
\end{array}\right]
$$

Hence, from this matrix (23) and considering equations (20), (21), and (22), the three phase currents are defined as:

$$
\begin{gathered}
I_{A}=I_{1}=\frac{V_{S} \pm V_{F A C T S}}{n_{F} \cdot Z_{A B .1} \pm X_{F A C T S}+\left(1-n_{F}\right) \cdot Z_{A B .1}} \\
I_{B}=a^{2} \cdot I_{1}=a^{2} \cdot \frac{V_{S} \pm V_{F A C T S}}{n_{F} \cdot Z_{A B .1} \pm X_{F A C T S}+\left(1-n_{F}\right) \cdot Z_{A B .1}} \\
I_{C}=a \cdot I_{1}=a \cdot \frac{V_{S} \pm V_{F A C T S}}{n_{F} \cdot Z_{A B .1} \pm X_{F A C T S}+\left(1-n_{F}\right) \cdot Z_{A B .1}}
\end{gathered}
$$

\section{CASE STUDY AND SIMULATION RESULTS}

The $400 \mathrm{kV}, 50 \mathrm{~Hz}$, electrical network studied in this paper is the Algerian electrical network which is shown in Fig. 5. The MHO distance relay is located on the busbar at Salah Bey substation to protect the single transmission line between busbar $A$ and busbar $B$ at Bir Ghbalou substation. The parameters of the transmission line and the series FACTS device installed in the mid of the line are summarized in Appendix.

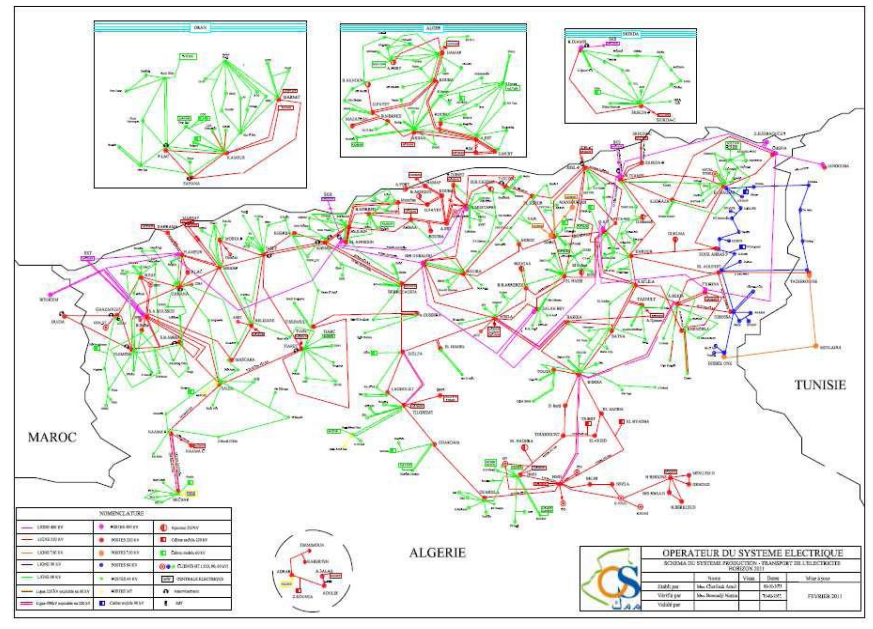

Figure 5. Algerian electrical network, [29]. 
Fig. $6(\mathrm{a}, \mathrm{b}$ and $\mathrm{c})$ represent the variation of the symmetrical component currents $I_{1}, I_{2}$ and $I_{0}$, respectively. Fig. 7 (a, b and c) represent the variation of line currents $I_{A}, I_{B}$ and $I_{C}$, respectively as a function of the conduction angle for three controlled series FACTS device TCSC, GCSC and TCSR.

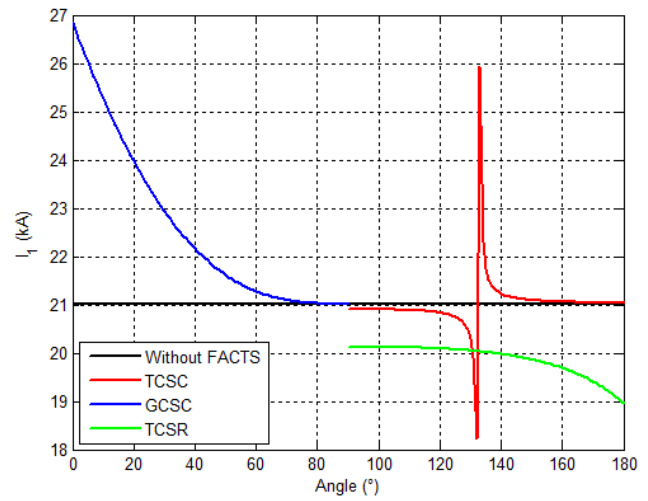

(a)

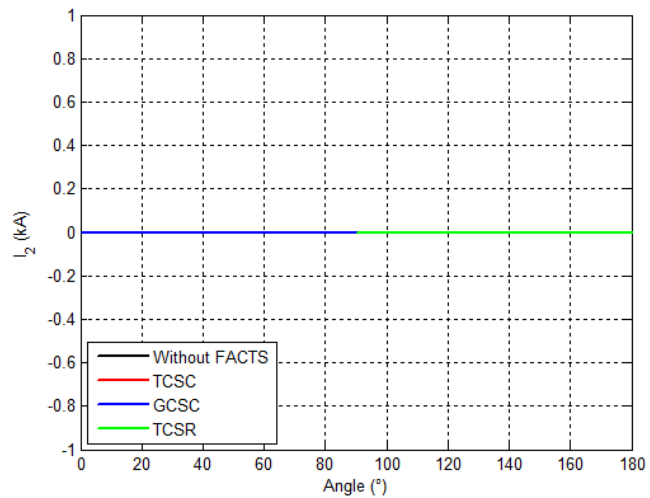

(b)

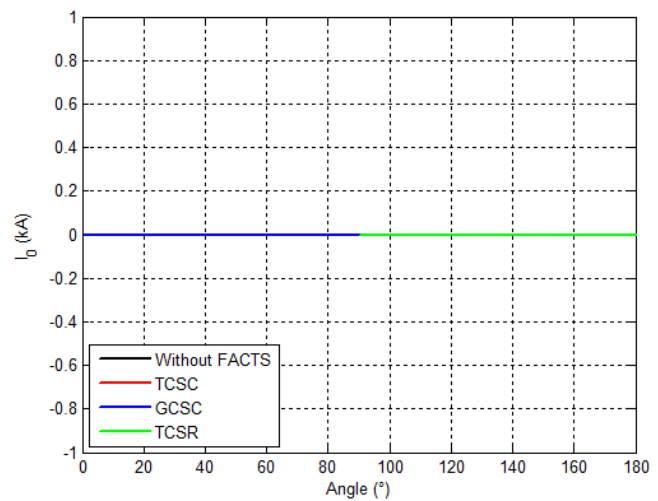

(c)

Figure 6. Impact of series FACTS on symmetrical currents.

a) $I_{1}=f($ Angle $)$, b) $I_{2}=f($ Angle $)$, c) $I_{0}=f($ Angle $)$.

From Fig. 6, without using FACTS devices, $I_{I}$ is equal to $21.0167 \mathrm{kA}$. However, in the presence of series FACTS devices, this value varies according to the compensators and varies as a function of the conduction angle. The two currents $I_{2}$ and $I_{0}$ are equal to zero value whether the case study is with or without using the FACTS devices, which verifies equations (21) and (22).

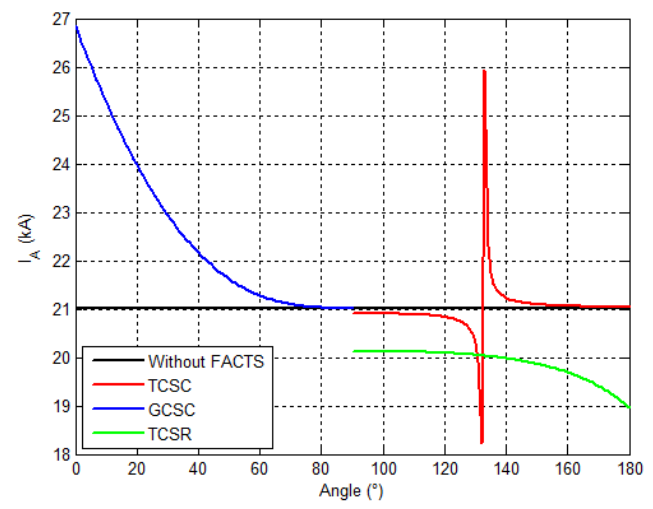

(a)

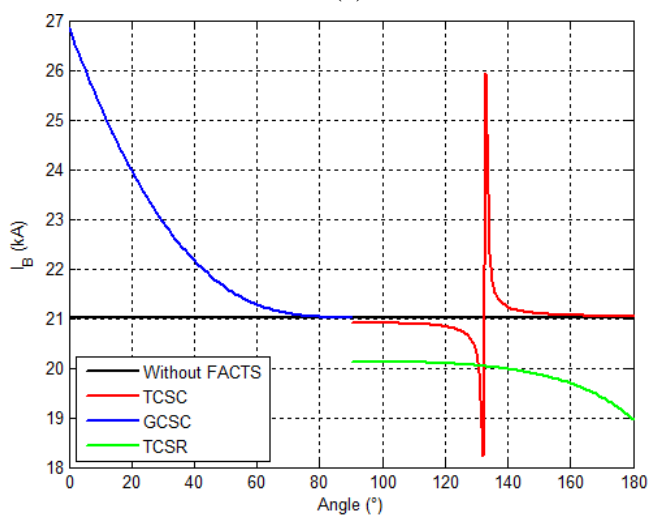

(b)

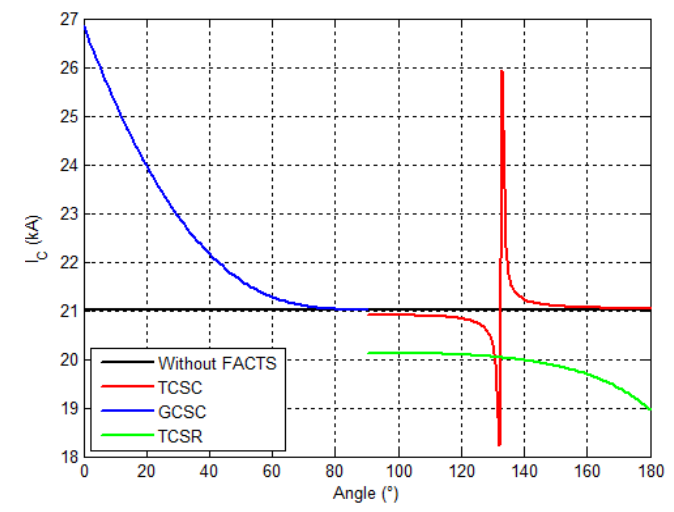

(c)

Figure 7. Impact of series FACTS on transmission line currents.

$$
\text { a) } I_{A}=f(\text { Angle }) \text {, b) } I_{B}=f(\text { Angle }) \text {, c) } I_{C}=f(\text { Angle }) \text {. }
$$

From Fig. 7 ( $a, b$ and $c$ ), without using FACTS, the three transmission line currents are equal to $21.0167 \mathrm{kA}$. When using any of the series FACTS devices at the mid of the transmission line, this value changes, increasing or decreasing, depending on the compensators. The currents vary as a function of the conduction angle, which verifies equations (24), (25) and (26). 
Fig. 8 ( $a, b$ and c) represent the variation of the symmetrical component voltages $V_{l}, V_{2}$ and $V_{0}$. Fig. 9 (a, b and c) represent the variation of the line voltages $V_{A}, V_{B}$ and $V_{C}$, as a function of the conduction angle for each of the three series FACTS devices TCSC, GCSC and TCSR.

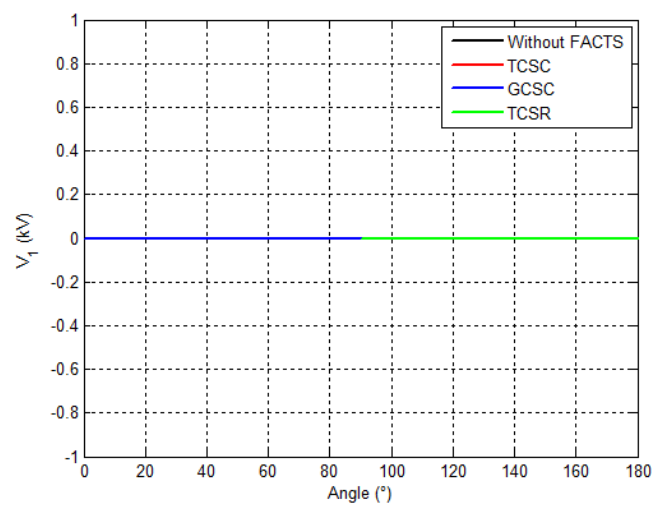

(a)

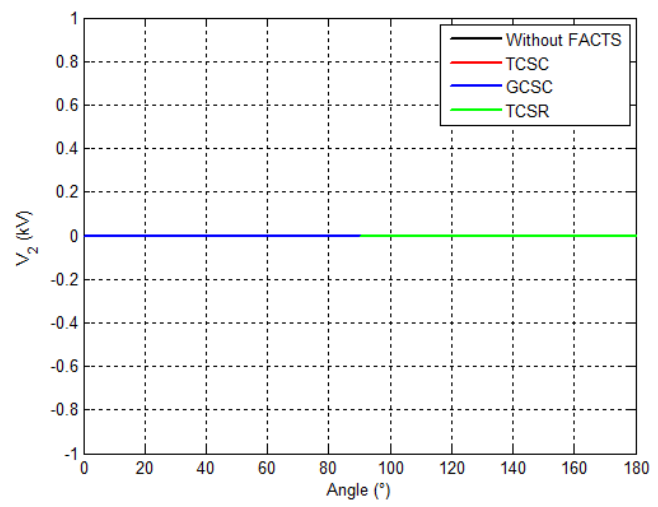

(b)

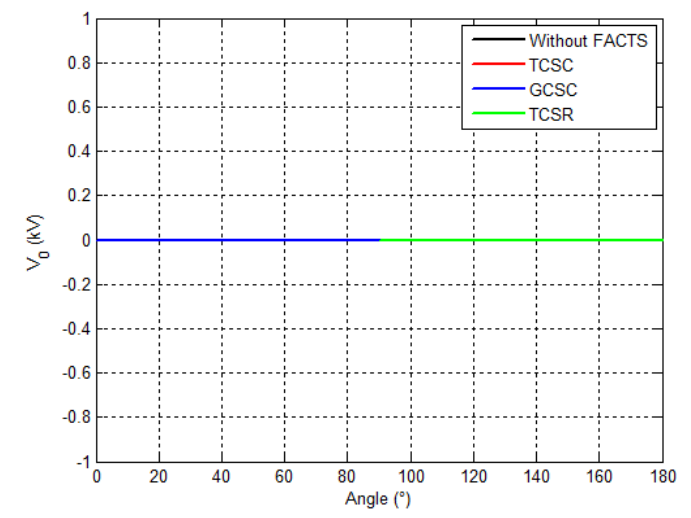

(c)

Figure 8. Impact of series FACTS on symmetrical voltages.

a) $V_{1}=f($ Angle $)$, b) $V_{2}=f($ Angle $)$, c) $V_{0}=f($ Angle $)$.

From Fig. 8 (a, b and c), the three symmetrical voltages are equal to zero value whether the case study is with or without using FACTS devices which verifies equations (16), (18) and (19).

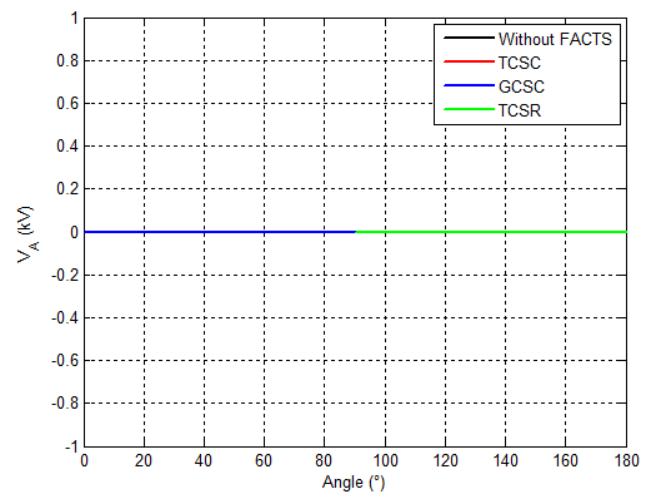

(a)

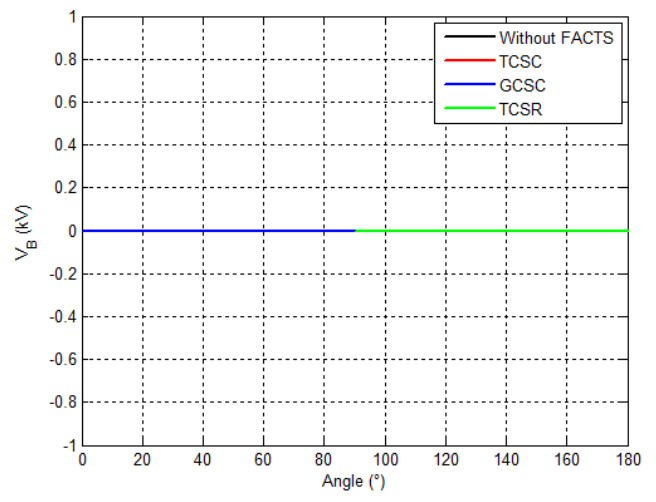

(b)

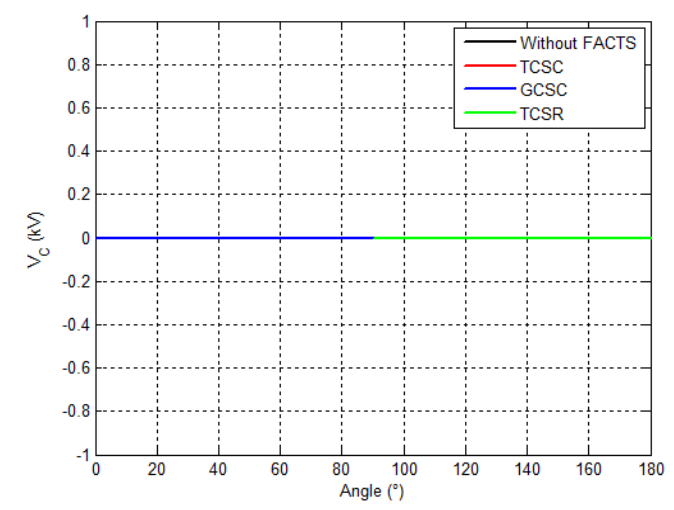

(c)

Figure 9. Impact of series FACTS on transmission line voltages. a) $V_{A}=f($ Angle $)$, b) $V_{B}=f($ Angle $)$, c) $V_{C}=f($ Angle $)$.

From Fig. 9 (a, b and c), transmission line voltages are equal to zero whether the case study is with or without using FACTS devices which verifies equation (15).

\section{CONCLUSIONS}

This paper studies the impact of the conduction angle of power electronic switches in series FACTS devices on the short circuit parameters in case of three phase fault. The fault is located at the end of a high voltage transmission line in the $400 \mathrm{kV}$ Algerian power network. The total impedance and powers transmitted on the line are influenced by the parameters of the controlled series FACTS devices, namely 
the conduction angles of the power electronic valves. Hence, the short circuit calculations are directly dependent on the conduction angle. For each value, the proposed method calculates new parameters for short-circuit and consequently, the magnitude of the fault current varies. In order to increase the total system protection performance when using series FACTS devices on transmission lines, care must be taken, mainly concerning the variation of fault current magnitude. This is crucial in adjusting the settings of the different protection devices of the high voltage transmission line; such as distance and overcurrent relays. This will certainly avoid the unwanted tripping of circuit breakers and improve the performance of protection relays.

\section{REFERENCES}

[1] J. Schlabbach, "Short-Circuit Currents", second edition, Published by the Institution of Engineering and Technology (IET), London, UK, 2008.

[2] G. Zigler, "Numerical Distance Protection : Principles and Applications", tthird edition, Publics Corporate Publishing, June 2008.

[3] Group Sonelgaz/OS, "Rapport: Statistics of Faults on Electrical Networks 220 and 400 kV", Algiers, Algeria, December 2012.

[4] C. Myeon-Song, and al., "Direct Three Phase Circuit Analysis based Fault Location for Line-to-Line Fault", IEEE Transactions on Power Delivery, Vol. 22, No. 4, pp. 2541-2547, 2007.

[5] H. Shateri, and S. Jamali, "Impedance based Fault Location Method for Phase to Phase and Three Phase Faults in Transmission Systems", $11^{\text {th }}$ IET International Conference on Developments in Power Systems Protection (DPSP), Birmingham, UK, 23-26 April 2012.

[6] A.A. Yusuff, A.A. Jimoh, and J.L Munda, "Determinant-based Feature Extraction for Fault Detection and Classification for Power Transmission Lines", IET Generation, Transmission \& Distribution, Vol. 5 , No. 12, pp. 1259-1267, 2011.

[7] M. Zellagui, A. Chaghi, H. Hassan, A. Ghodbane and A. Ghorbani, 'Impact of Fault Resistance on Transmission Line Compensated by Series FACTS Devices', International Conference on Electrical Engineering and Automatic Control (ICEEAC'2013), Faculty of Technology-Setif 1 University, Setif, Algeria, 24-26 November, 2013.

[8] A. Ukila, S.Chenb, and A. Andennaa, "Detection of Stator Short Circuit Faults in Three-Phase Induction Motors using Motor Current Zero Crossing Instants", Electric Power Systems Research, Vol. 81, N. 4, pp. 1036-1044, 2011.

[9] A. Gaeta, G. Scelba, and A.Consoli, "Modeling and Control of Three-Phase PMSMs Under Open-Phase Fault", IEEE Transactions on Industry Applications, Vol. 49, No. 1, pp. 74-83, 2013.

[10] N. Bahador, A. Darabi, and H. Hasanabadi, Demagnetization Analysis of Axial Flux Permanent Magnet Motor Under Three Phase Short Circuit Fault, $4^{\text {th }}$ Power Electronics, Drive Systems and Technologies Conference (PEDSTC), Tehran - Iran, 13-14 Feb. 2013.

[11] K.W. Klontz, T.J.E. Miller, M.I. McGilp, H. Karmaker, and P. Zhong, "Short-Circuit Analysis of Permanent-Magnet Generators", IEEE Transactions on Industry Applications, Vol. 47, No. 4, pp. 1670-1680, 2011.

[12] P.S. Peerez, and J. Driesen, "Impact of Wind Turbines Equipped with Doubly-Fed Induction Generators on Distance Relaying", IEEE Power and Energy Society General Meeting, Minneapolis, USA, 2529 July 2010.

[13] A. Rolán, F. Córcoles, and J. Pedra, "Doubly Fed Induction Generator Subject to Symmetrical Voltage Sags", IEEE Transactions on Energy Conversion, Vol. 26, No. 4, pp. 1219-1229, 2011.

[14] M. Mirhosseiniand, and V.G. Agelidis, "Performance of Large Scale Grid Connected Photovoltaic System Under Various Fault Conditions", IEEE International Conference on Industrial Technology (ICIT), Cape Town - Australia, 25-28 February 2013.
[15] T.S. Sidhu, and D. Bejmert, "Short-Circuit Current Contribution from Large Scale PV Power Plant in the Context of Distribution Power System Protection performance", IET Conference on Renewable Power Generation (RPG), Edinburgh - UK, 6-8 September 2011.

[16] O. Ting-Chia, "A Novel Unsymmetrical Faults Analysis for Microgrid Distribution Systems", International Journal of Electrical Power \& Energy Systems, Vol. 43, No. 1, pp. 1017-1024, 2012.

[17] K.K. Sen, and M.L. Sen, "Introduction to FACTS Controllers: Theory, Modeling and Applications", John Wiley \& Sons, Inc., and IEEE Press, New Jersey - USA, 2009.

[18] X.P. Zhang, C. Rehtanz, and B. Pal, "Flexible AC Transmission Systems: Modelling and Control", published by Springer Publishers, Heidelberg, Germany, 2006.

[19] K.K. Sen, and M.L. Sen, "Introduction to FACTS Controllers: Theory, Modeling and Applications", Published by John Wiley \& Sons, Inc., and IEEE, New Jersey, USA, July 2009.

[20] L.F.W. de Sow, E.H. Watanabe and M. Aredes, "GTO Controlled Series Capacitors: Multi-Module and Multi-pulse Arrangements", IEEE Transactions on Power Delivery, Vol. 15, No. 2. pp. 725-731, April 2000.

[21] M. Zellagui, and A. Chaghi, "Measured Impedance by $M H O$ Distance Protection for Phase to Earth Fault in Presence GCSC", ACTA Technica Corviniensis - Bulletin of Engineering, Tome 5, Fas. 3, pp. 81-86, 2012.

[22] M. Zellagui, and A. Chaghi, "Impact of Apparent Reactance Injected by TCSR on Distance Relay in Presence Phase to Earth Fault", Advances in Electrical and Electronic Engineering (AEEE), Vol. 11, No. 3, pp. 156-168, 2013.

[23] M. Zellagui, and A. Chaghi, "Distance Protection Settings Based Artificial Neural Network in Presence of TCSR on Electrical Transmission Line", International Journal of Intelligent Systems and Applications (IJISA), Vol. 4, No. 12, pp. 75-85, November 2012.

[24] P.M. Anderson, "Analysis of Faulted Power Systems", published by IEEE Press, New York - USA, 1973.

[25] N.D Tleis, "Power Systems Modelling and Fault Analysis: Theory and Practice", Published by Elsevier Limited, Oxford - UK, 2008.

[26] D. Sweeting, "Applying IEC 60909, Fault Current Calculations", IEEE Transactions on Industry Applications, Vol. 48, No. 2, pp. 575580, 2012.

[27] C.L. Fortescue, "Method of Symmetrical Coordinates Applied to the Solution of Polyphase Networks", Transactions of AIEE, Vol. 37, pp. 1027-1140, 1918.

[28] J. Lewis Blackburn, and A.F. Sleva, "Symmetrical Components for Power Systems Engineering”, second edition, published by CRC press, London - UK, 2011.

[29] Sonelgaz Group, "Topolgy of Electrical Transmssion Networks High Voltage", Algerian Company of Electrical Transmission, GRTE, Algiers, Algeria, 30 December 2013.

\section{APPENDIX}

\section{A. Transmission line}

$U_{L}=400 \mathrm{kV}$, Length $=205 \mathrm{~km}$,

$Z_{1}=0.0291+j 0.3081 \Omega / \mathrm{km}$,

$Z_{0}=0.0873+j 0.9243 \Omega / \mathrm{km}$.

\section{B. TCSC}

$Q_{\text {Max }}=31 /-42$ MVar, $V_{\text {Max }}=18 /-22 \mathrm{kV}, C=8.30 \mu \mathrm{F}$,

$L=0.19 \mathrm{mH}$.

C. GCSC

$Q_{\text {Max }}=-60 \mathrm{MVar}, V_{\text {Max }}=-30 \mathrm{kV}, C=212.20 \mu \mathrm{F}$.

D. TCSR

$Q_{\text {Max }-L 1}=70 \mathrm{MVar}, Q_{\text {Max }-L 2}=30 \mathrm{MVar}, V_{\text {Max }-L l}=20 \mathrm{kV}$,

$V_{\text {Max }-L_{2}}=10 \mathrm{kV}, L_{l}=10.610 \mathrm{mH}, L_{2}=18.189 \mathrm{mH}$. 